(昭和 32 年 4 月 20 日受理)

織物の粘弾性に䦎する研究

第 5 報 織物の構造と曲げ挙動について

\author{
俉州大学蟣維学部 呉 祐吉・篠原 昭・松橋房江 \\ VISCOELASTIC STUDIES OF TEXTILE FABRICS (V) ON THE \\ RELATIONSHIP BETWEEN THE BENDING BEHAVIOURS OF \\ FABRICS AND FABRIC STRUCTURES
}

By Yukichi Go, Akira Shinohara and Fusae Matsuhashi

(Faculty of Textiles, Shinshū University, Ueda, Japan)

The flexible rigidities ( $E I$ ) of the many kinds of fabrics (Table 1) are measured by heart loop method.

(1) EI of fabric depends upon the bending mode of test piece. An $E I$ of fabric having the long floats on its surface is smaller in face-to-face bending than back-to-back. (Fig. 1 \& 2)

(2) An EI of low freeness fabric is generally small, but there are many deviations from this tendency, e.g. in basket weaves.

(3) An effect of crimp of component yarn of fabric to the EI of fabrics is generally small. When the crimp is of sine wave, apparent rigidity $D_{a}$ is :

$$
D_{a}=\frac{E I}{\left(1+\sigma^{2}\right)}
$$

Where $\sigma: a / b \pi, a$ : amplitude, $\mathrm{b}$ : the length of period. So, in the case of $\sigma \ll \mathrm{l}$, a crimp efiect is very small and neglegible, ordinary fabrics are in this category.

(4) The flexible rigidity of yarn calculated by means of dividing the fabric rigidity with yarn density $E I(F)$ are generally larger than the true rigidity $E I(T)$ of compornent yarn measured by the experiment.

The rigidity factor $S$ may can be descriced in general as;

$$
S=E b\left(\frac{h}{l}\right)^{s} \phi\left(\frac{G}{E}, \lambda\right),
$$

where $l$ is true length contributing to yarn bending. In the ordinary fabrics, warp and weft yarns come in contract each other not at geometrical contact point but in contact length. So, true length 1 is shorter than in the case of ideal geometrical fabric model, i. e. $l_{0}=n l$.

i. e. $S$ is proportional to $n, n^{*} E I(T)=E I(F)$.

In the ordinal clothing fabrics, $n=1 \sim 1.16$ (Table $3 \& 4$ )

We find that the bending mechanism of fabrics could be explained as the function of the rigidity of compornent yarn and fabric structure.

(Received 20. 4. 1957)

\section{1. 緒霅}

織物の曲げ剛さは，従来織物の柔軟性あるいは手触り (handle) の尺度として用いられ，それの測定法その他 について多くの研究がなされているリ。机われは綿織 物の曲け゚風さと,その織物構造との関係执よび,さらに各 棈成系の性質との等係を研究し，曲げの大変形の一つで ある樴物の防䖵性との関保についても，合わせ考察した。
織物組織と柔軟性との関係については絹織物試料につ いて，すでに三浦，内田2) 氏らが報告しているが，本報 では曲げの詳しい機構, 特に幾何学的な織物構造に注目 して研究をすするた結果を報告することにした。

\section{2. 試料および方法}

試料は第 4 報ふのものと同一のを用いた。すなわち経， 䋨系とす 80 番双, 密度はともにはぼ $40($ 本 $/ \mathrm{cm})$ のる 
のである。測定方法は最初振動りード法を用いたが，变 形が小さいことと，折り曲げ方 (表・裹)を区別できな いので，F.T. Peirce の方法党用いることにした。こ の試料は未加工，糊抜したもので，比較的柔かなため， いわゆる片持梁法では bending length を正磪に测定で きないので，heart loop 法を用いることにした。試料の 大さは巾 $1 \mathrm{~cm}$ (密度を撤文るようにした)，試料長 16 cm とし, その懸垂長 (clamp の上端から試片の最下端 までの苦直距離) を読取顕微鏡で測定し，10回の平均を とつた。坪量はトーションバランスで各試片について湘 定した。な和測定条件は $20^{\circ} \mathrm{C} ， 65 \%$ R.H. である。

\section{3. 結果および考察}

Table. 1 K湘定結果を示した。以下数節に分けて梌 草した。

\section{(1）折り曲げ方による曲げ䙲さの相違}

平織およびサージのような両面綾のものでは製織上あ るいは加工面の表裹とは別の，組織上の表裹の相違はな い。しかし 1/3，1/7 斜文のよ5ないわゆる片面綾におい ては、経䋨の浮きの長さに差があり，表裏の構造が著しく 異つている。いま $1 / 7$ 斜文を引例して説明してみる。

いま Fig.1 の $A A^{\prime} ， B B^{\prime}$ で切断したときの $1 / 7$ 斜文 の断面を模式的に示すと Fig. 2 のよ5になる。闵に折

Table. 1

\begin{tabular}{|c|c|c|c|c|c|c|c|c|c|c|c|}
\hline \multirow{2}{*}{$\begin{array}{c}\text { Sample } \\
\text { No. }\end{array}$} & \multirow{2}{*}{\multicolumn{2}{|c|}{ Weaves }} & \multirow{2}{*}{$\begin{array}{c}\text { Free- } \\
\text { ness }\end{array}$} & \multirow{2}{*}{$\begin{array}{l}10^{2} \times w \\
(\mathrm{~g} / \mathrm{cm})\end{array}$} & \multicolumn{4}{|c|}{$E I\left(\right.$ dyne $\left.\cdot \mathrm{cm}^{2}\right)$} & \multicolumn{2}{|c|}{ Crease $\begin{array}{c}\text { Reco- } \\
\text { very }\left({ }^{\circ}\right)\end{array}$} & \multirow{2}{*}{$\begin{array}{c}E I(F) \\
\left(\begin{array}{c}\text { dyne } \\
\left.\mathrm{cm}^{2}\right)\end{array}\right.\end{array}$} \\
\hline & & & & & $W-1$ & $F-2$ & $W-2$ & $F-1$ & $W$ & $F$ & \\
\hline 1 & Plain Weaves & & 32 & 1.27 & 51.1 & 49.2 & & & 71 & 66 & 1.24 \\
\hline 2 & $2 / 2$ War Rib & & 16 & 1.62 & 60.0 & 121.9 & & & 72 & 68 & 1.53 \\
\hline 3 & 2/2 Basket & & 8 & 1.30 & 55.0 & 51.4 & & & 77.5 & 69 & 1.34 \\
\hline 4 & $4 / 4 \quad \prime \prime$ & & 2 & 1.26 & 51.5 & 50.0 & & & 86 & 92 & 1.32 \\
\hline 5 & Fancy \& Figured & $" 1 "$ & 10 & 1. 42 & 49.2 & 50.5 & & & 79 & 83.5 & 1.20 \\
\hline 6 & $1 / 3$ Twills & & 16 & 1.39 & 33.6 & 54.2 & 61.3 & 49.1 & 75 & 86 & 0.75 \\
\hline 7 & 1/3 Broken & & 16 & 1.39 & 44.9 & 48.6 & & & 71.5 & 85 & 1.12 \\
\hline 8 & $2 / 2$ Twills & & 16 & 1.40 & 46.3 & 45.0 & & & 80.5 & 83 & 1.13 \\
\hline 9 & 2/2 Broken & & 20 & 1.38 & 51.5 & 48.0 & & & 69 & 69.5 & 1.29 \\
\hline 10 & $2 / 2$ Herring Bone & & 18 & 1.30 & 51.0 & 50.0 & & & 70 & 80 & 1. 27 \\
\hline 11 & Pointed Twills & & 16 & 1.33 & 49.7 & 57.9 & & & 87 & 76 & 1.22 \\
\hline 12 & $\frac{112}{112} \quad \prime \prime$ & & 24 & 1.27 & 51.0 & 47.6 & & & 73 & 70.5 & 1.27 \\
\hline 13 & $\frac{111}{113}$ & & 24 & 1.30 & 68.9 & 56.5 & & & 69 & 69.5 & 1.68 \\
\hline 14 & $\frac{11}{15}$ & & 16 & 1.40 & 41.5 & 45.9 & 45.4 & 41.0 & 72 & 71 & 0.94 \\
\hline 15 & $\frac{1}{7} \quad \prime \prime$ & & 8 & 1.32 & 49.7 & 58.1 & 50.0 & 49.2 & 87 & 95.5 & 1.16 \\
\hline 16 & Entwining " & & 8 & 1.25 & 52.8 & 49.5 & 54.2 & 52.8 & 78.5 & 90.0 & 1. 26 \\
\hline 17 & $2 / 6$ & & 8 & 1.38 & 51.4 & 49.5 & 51.7 & 50.0 & 88 & 98.25 & 1.25 \\
\hline 18 & $3 / 5$ & & 8 & 1.39 & 48.9 & 58.1 & 54.3 & 49.7 & 87.5 & 83.6 & 1.16 \\
\hline 19 & $4 / 4 \quad 11$ & & 8 & 1.38 & 47.7 & 52.8 & & & 85 & 85.9 & 1.08 \\
\hline 20 & $\frac{211}{121}$ Steep & & 16 & 1.30 & 39.5 & 58.6 & & & 82.5 & 93.5 & 0.96 \\
\hline 21 & 8 Harness Satins & & 8 & 1.31 & 40.1 & 51.8 & 53.1 & 51.4 & 95 & 99.4 & 1.02 \\
\hline 22 & Granite Weaves & & 24 & 1. 49 & 62.2 & 59.7 & & & 70 & 74 & 1. 48 \\
\hline 23 & Sponge & & 28 & 1.50 & 53.5 & 63.0 & & & 71.5 & 78.8 & 1.24 \\
\hline 24 & Huck-a-Back " & & 24 & 1.42 & 53.8 & 84.9 & 58.1 & 54.0 & 81.25 & 64.0 & 1.24 \\
\hline 25 & Honey-Comb " & & 19 & 1.61 & 128.5 & 111.9 & & & 113.5 & 102.5 & 2.94 \\
\hline 26 & Imitation Gauzes & & 16 & 1.44 & 52.8 & 58.8 & & & 74 & 83 & 1.32 \\
\hline 27 & Grecian Weaves & & 14 & 1.29 & 49.6 & 47.8 & & & 88 & 85.5 & 1.11 \\
\hline
\end{tabular}

In table, $w$ : weight per unit length of sample fabric, $W$ and $F$ : Warp and filling ways respectively, suffixes 1.2 show bending mode, see Fig. 2 .

*The angle allowed to recover in $20 \mathrm{~min}$ after the weight $(500 \mathrm{~g})$ is removed, (weighting time, 5 min.). An apparatus is Monsanto type crease tester, modified in our laboratory. 


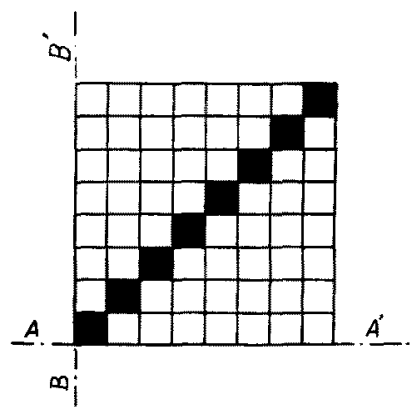

Fig. 1

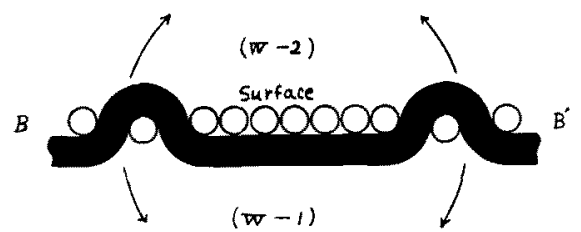

(i)

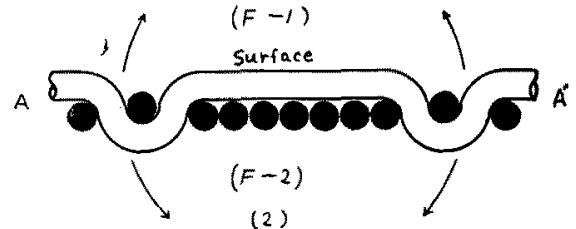

Fig. 2 Diagramatical explanation of bending modes, citing an instance of $1 / 7$ twills, $W$ and $F$ show the bending of warp and weft respectively. In the figure, the block is of warp and the ather the weft.

者は逆に反対方向の系が曲げの内側にあるので，曲げの 提抗は大きくなる管ですり，8種数についての結果を Table.1 K示してある。曲汗剛さ $E I$ の大さは大隹 $(W$ $-2)>(W-1),(F-2)>(F-1)$ で, $\$$ た $(W-1)$ と $(F-1)$

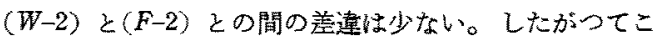
のよ5な組峨のものでは，曲げ㓮さが測定曲率によつて かなり変化することが想想される。一䏯氏4は綿系扣よ び綿布の曲げモーメントと曲率との閔係を実験し，网者 と名曲菜の小さいときは曲げモーメントが急に增加する こをを報告しているがこれは瀻維それ自身の力学的性 質に传存するものと解すべきものと考える。

\section{(2)斩り曲げ方向による堙異}

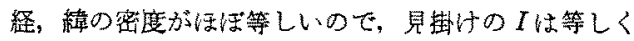
なるはずであるが，多くの研究者にるつて指摘されてい

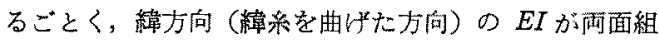
織の場合，やや小さくなつている。2の2本経嘼は緯方

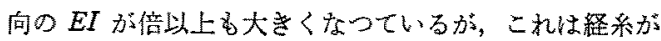
䋨系の曲げに対して抵抗するからではないかと思 5。類
似の傾向は 20 の急斜文にる邓られる。また两面綾につ いては前述のごとくである。斜め方向 (bias) について

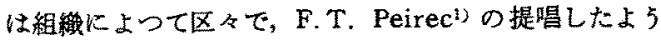

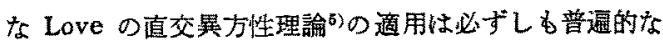

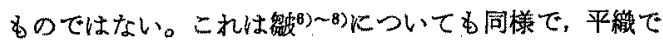
はややこれに近い結果がえられているが，綾織では斜文 楾の力向が防瀿性が䓪いことが知られている。しかし力

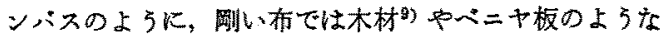
合板 ${ }^{10)}$ ，硝子瀻維の強化したポリエステル板 ${ }^{12}$ のような 典型的な直交異万性を示するのと思われる。これの詳紐 は改めて翰で報告する。

\section{（3）組織に上る美異}

一般に自由度の大きいるのては $E I$ は小さい傾向があ るが，3,4の斜子は必ずしもこの範德には入らない。こ れは絹布についての内田氏らの実験結果す同様である。 また 6 と，15と 16 のよ では前者の方がやや EI は小さい。

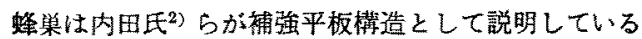
よ3に，他の組織に比し $E I$ は非常に大きい。これは防

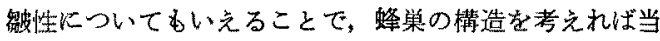
然考えられることである。

\section{(4) 糸の crimp 效果}

徉来，布の曲计の研究怯布安 1 枚の弾性板として取报 つて㧊つた。布は経系および緯紋からなつており，経方

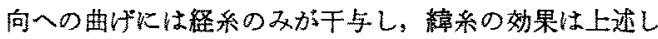

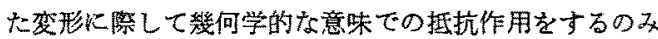
である。したがつて経・緯系の力学的な性筫と幾何学的

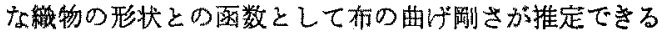
ことが織物設計上はもとより，要らゆる点で望をれるこ とである。

われわれは布を構成している杀が crimp しているこ とから，布が擬似的には一種の波板様のものではないか と考えた。しかし布は板と異り，あく迄电 crimpした一 次元の䒺が並んだものであるから，全体の举動は個及の crimp した糸の総和となるはずである（横絡の効果を無 視して)。

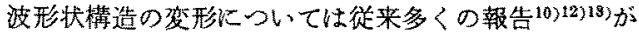
あり，网さ係数も求められているが，われわれはごく简 単に契駼に便利な形で，これを解析してみた。いま波形

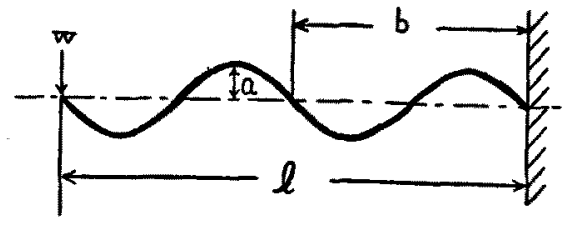

Fig. 7 
学振巾 $a$, 波長 $b$ の正弦状のものとする。すなわち

$$
y=a \sin \frac{2 \pi}{b} x
$$

しかるときの見卦けの曲げ判さは系自体の $E I$ とは多 少違5はずである。いま Fig. 3 のよ5な片持梁状の曲 げを考えるカスチリアノの定理を用いて微少㩭みるを求 めてみる, 霆エネルギーを $U$ とすると

$$
\delta=\frac{\partial U}{\partial W}=\frac{1}{E I} \int_{0}^{l} M \frac{\partial M}{\partial W} d S .
$$

ここて W は荷重， $M$ はモーメント， $S$ は曲線に沿 つた長さである。

$M=W x, \partial M / \partial W=x$

$\left.d S=\sqrt{1+\left(\frac{d y}{d x}\right)^{2}} d x=\sqrt{1+(2 \pi)^{2} \frac{a^{2}}{b^{2}} \cos ^{2} \frac{2 \pi}{b} x d x}\right\}$ (3) $\left(2 \pi \cdot \frac{a}{b}\right)^{2}=\lambda^{2}, 2 \pi / b=p$ と扰き（3）を(2)に代入 すると，

$$
\delta=\frac{W}{E I} \int_{0}^{l} x^{2} \sqrt{1+\lambda^{2} \cos ^{2} p x} d x
$$

入は無次元量であり，また一般に普通の布では 1 より 小さな值となり，したがつて（4）式のルートを級数に 展開すると，W/EI=K とおいて

$$
\delta=K \int_{0}^{l}\left(x^{2}+\frac{1}{2} \lambda^{2} x^{2} \cos ^{2} p x-\frac{1}{8} \lambda^{4} x^{2} \cos ^{4} p x+\cdots\right) d x
$$

(5)式右扨第 3 項以下を近似的に省略する。第 2 項の 積分は $p x=t$ と括くと

$$
\begin{aligned}
I_{n} & =\int_{0}^{l} x^{2} \cos ^{2} p x d x=\frac{b^{3}}{32 \pi^{3}}[t \cos t \cdot(2 \cos t+2 t \sin t) \\
& \left.+\frac{2}{3} t^{3}-t-\frac{1}{2} \sin 2 t\right]_{0}^{2 n \pi}=\frac{1}{4}\left(\frac{2}{3} l^{3}+\frac{b^{2}}{4 \pi^{2}} l\right)
\end{aligned}
$$

ここで $n$ は $l / b$ て $2 n$ が整数になるような $l$ でれ ば（自由端と国定端が同一楾上にあれば） sineの値は0 となることを利用している。

$$
\therefore \delta=\frac{W l^{3}}{3 E I}\left[1+\frac{\lambda^{2}}{4}\left(1+\frac{3}{8 \pi^{2} n^{2}}\right)\right]
$$

$l / b=n$ と拈いた $n$ はlの中にある波長の数であるか ら（6）式の小括弧内第 2 項は 1 に対して省略できるの ז

$$
\delta=\frac{W l^{8}}{3 E I}\left(1+\frac{\lambda^{2}}{4}\right)
$$

$\lambda=0$ の場合はいうまでもなく真直ぐな棒や板の場合 に他ならない。(7)式を慧さ直すと $\lambda / 2=\sigma と$ といて

$$
\frac{E I}{\left(1+\sigma^{2}\right)}=\frac{W l^{3}}{3 \delta} \equiv D_{a}
$$

となり，見措けの曲げ風さ $D_{a}$ が求ま百。の゙が大きい程 crimp の大きい程同一条件で撓みが大きくなる。すな わち見掛けの曲げ䦌さは小さくなる。なお波形調子板に ついて永盛氏 ${ }^{14)}$ らが類似の取报をしていることが後日か
かつた。

crimp が正弦状であるのは平織やサージの上5な場合 のみであつて，片面綾などは解析は困難であるが，フー リェ一級数で波形を表わぜば，解析る可能である。たと えば 4/4 斜子の上5な浮き長いるのでは，波長の長い 正弦波と一種の短形波との中間のもので，いわば不完全 矩形波である。この場合には

$$
\begin{aligned}
& y=a+\frac{4 a}{\pi} \sum_{m=0} \frac{\sin (2 \pi)(2 m+1) x / b}{2 m+1} . \\
& \left(y^{\prime}\right)^{2}=\frac{16}{\pi^{2}} \lambda^{2} \sum_{A} \sum_{B} \cos A x \cdot \cos B x
\end{aligned}
$$

ここで $A=(2 \pi)(2 m+1) \mid b, \quad B=(2 \pi)(2 n+1) / b$ で $\sum_{A}, \sum_{B}$ は $m, n=0$ からゆまでの和を示するのである。 故に撓 $\delta$ は (5) 式と同様

$$
\begin{aligned}
\delta & =\frac{W}{E I} \int_{0}^{l} x^{2}\left(1+\frac{8}{\pi^{2}} \lambda^{2} \sum_{A} \sum_{B} \cos A x \cdot \cos B x\right. \\
& \left.-\frac{32}{\pi^{4}} \lambda^{4} \Sigma \Sigma \Sigma \Sigma \cos A x \cdot \cos B x \cdots+\cdots\right) d x \\
& \div \frac{W}{E I} \int_{0}^{l} x^{2}\left(1+\frac{8}{\pi^{2}} \lambda^{2} \sum_{A} \sum_{B} \cos A x \cdot \cos B x\right) d x
\end{aligned}
$$

第 2 項の積分 $I_{n}$ は

$$
\begin{aligned}
I_{n} & =\sum_{A} \sum_{B} \int_{0}^{l} x^{2} \cos A x \cdot \cos B x d_{x} \\
& =\sum_{A} \sum_{B}\left[x^{2} f(x)\right]_{0}^{l}-2 \sum_{A} \sum_{B} \int_{0}^{l} x f(x) d x \\
& =\sum_{Q} \sum_{N}\left[x^{2} f(x)-\frac{1}{Q^{3}}(\sin Q x-Q x \cos Q x)\right. \\
& \left.-\frac{1}{R^{3}}(\sin R x-R x \cos R x)\right]_{0}^{l} \ldots \ldots \ldots \ldots \ldots \ldots
\end{aligned}
$$

たたし

$$
f(x)=\frac{\sin Q x}{2 Q}+\frac{\sin R x}{2 R}, Q=A-B, R=A+B
$$

$A=B$ ならば前述の一般的の場合と全く一致する。 $A$ $\sim B$ が大きければ $Q, R$ と6大きなり（m，nは共に 整数であるので） $I_{n}$ は小さくなるから，A〜Bの小さい 筙四について総和すればよいことになり，いずれにせよ crimp 効果はさらに僅少になる。

\section{（5）糸の曲げ刷さと織物の曲げ刷さとの関係}

製織に用いた原系の曲げ剛さの平均は，次の上5にな る。

Table 2

\begin{tabular}{c|c|c}
\hline $\begin{array}{c}\text { bending length } \\
C\end{array}$ & weight per $\mathrm{cm}, w$ & $E I(T)$ \\
\hline $1.67 \mathrm{~cm}$ & $0.000161 \mathrm{~g} / \mathrm{cm}$ & $0.745 \mathrm{dyne} \cdot \mathrm{th}^{2}$. \\
\hline
\end{tabular}

布の曲げ剛さは愿さが一定ならげ試料の巾に攺经比例 することが知られている15)。今 Table 1 に示した $(W$ -1)の $E I$ の测定值を繙度で除して, 系 1 本当りの曲 げ用さを算出すると表の右端のよらな值になり，密度が 
大体一定であるので相当大きな偏位がある。笅密には前 節の crimp の補正を要するのであるが，これはほとん ど0とみなしてさしつかえない。すし布の曲け゚に対し， 反対方向の系(経系を曲げる場合には紿禾)の抵抗がない 場合には第 2 表に示した系の $E I$ と布の $E I$ から計算し

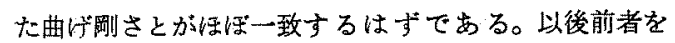
$E I(T)$, 後者を $E I(F)$ と書いて区别する。

実験からえた， $E I(F) の$ 中最も小さい1/3 斜文では $E I(F)=0.82$ となり, $E I(T)=0.745$ に近い值とな る。

織物の場合, 以上の諸測定值にはかなりの誤差が必然 的に介入してくるのであるが，このような考察から第 1 次的比 $E I(T)<E I(F)$ なる関俰の出ることはわかる。 この差は crimp 効果を補正すればわずかではあるが大 きくなる。このような偏位が生ずるのはやはり横系の効 果とみなすべきであるう。したがつてこの計算では無視 した布の構造因子をどのように導入すべきかについて一 つの仮定的な取报いを試みた。

横系奻果扎よび crimp 刘果が全くなければ, EI (T) $=E I(F)$ となり，本来雨者は全く同じはずのるのである したがつて実験でえられる見掛けの曲げ剛さは䈌密にい つて材力的な $E I$ とは多少違つた性質のるのてある。い ま慣例従つて“剛さ，Stiff ness”を力と撓みの比で表 わし，これを $S$ と报くと次元解析から

$$
S=E b\left(\frac{h}{l}\right)_{\phi}^{s}\left(\frac{G}{E}, \lambda\right)
$$

で表わせることが知られている16)。 $h$ は試料の厚さで横 系の存否に関係なく縦系の断面䅡に依存するものであり $b$ は試料の巾であるから $b h^{3}=I$ と拈くと $E I$ は系の形 とヤング率とから定まるすので一定とみなすと

$$
S=\frac{E I}{l^{\mathbf{s}}} \phi\left(\frac{G}{E}, \lambda\right)
$$

G 法制性率であるから申は無次元铻であり，一応無 視すると，剛さ $S$ は $l^{-8}$ 江比例することになる。

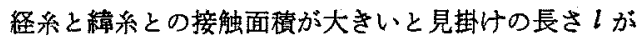
交錯点の曲率岁るい性系の偏平度によつて異つている。 い点接触の場合 (Fig.4-1)，その長さを $l_{0}$ ，一般の場 合たとえば Fig. 4-2 のように棈円と接する場合には接 触長さが長く，乙たがつて自由長は $l_{0}$ 上り短くなる。 これを $l=l_{0} / n$ とおくと，

$$
S_{0} l_{0}^{3}=S l^{3}=S\left(\frac{l_{0}}{n}\right)^{3}
$$

$S_{0} l_{0}^{8}=E I(T), S l_{0}^{8}=E I(F)$ であるから

$$
n^{3} E I(T)=E I(F)
$$

なる関係がえられる。すなわち系の曲げ用さ $E I(T)$ の $n^{s}$ 倍が織物の曲计剛さ $E I(F)$ と等しいことになる。n を実際测測定することは困難であるが，1例として $E I$
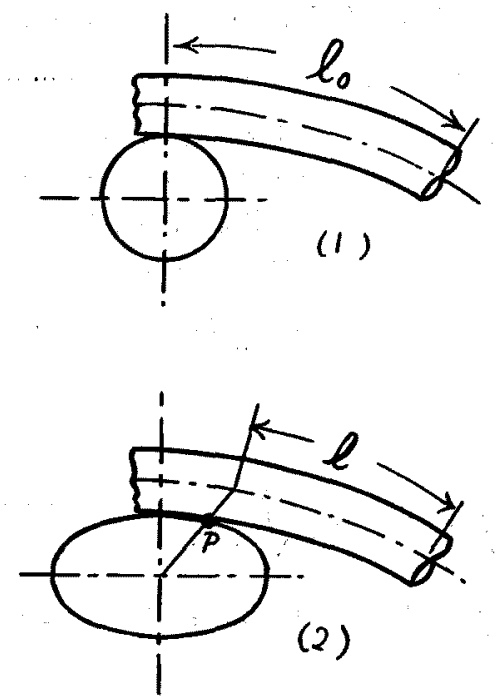

Fig. 4

$(T)=0.745 \mathrm{dynl} \cdot \mathrm{th}^{2}$. K系密度 41 本 $/ \mathrm{cm}$ を乘した 30. $545 \mathrm{dyne} \cdot \mathrm{cm}^{2}$ を基碳にして各種の $n$ 亿対する織物の (1 $\mathrm{cm}$ 巾の)曲げ用さを求めると Table. 3 のようになる。

Table. 3

\begin{tabular}{c|cccc}
\hline$n$ & 1 & 1.1 & 1.2 & 1.3 \\
\hline$E I(F) / \mathrm{cm}$ & 30.545 & 40.66 & 52.78 & 67.11 \\
\hline
\end{tabular}

以上は主として平織やfloat の短い綾織のような場合 に当てはまるるんとおるれる。

E.T.Peirce ${ }^{17)}$ は経緯糸がともに円形断面の平織につ いて，その接触角を算出しているが，それによると接触 部分の中心角を $2 \theta$ とすると

$$
\begin{aligned}
& \sin \theta=\frac{2 x}{x^{2}+1} \\
& x=\tan \frac{\theta}{2} \frac{l_{0}-\sqrt{l_{0}^{2}+H^{2}-D^{2}}}{D+H}
\end{aligned}
$$

ここで $2 D$ は経緯系の接点の中点を通り，両中心線を 結方距離, $H$ は布の断面の見措けの中心線からその線に 直角方向の糸の中心までの距離, $l_{0}$ は相隣る系の間隔で ある。(詳細は Peirce の原論文 Fig.1 参照)よつてn は

$$
n=\frac{l_{0}}{l_{0}-2 D \sin \theta}
$$

いま $l_{0}=8, D=2$ とし $H$ を 0 から 2 迄变化させ， $\sin \theta, n$ を求めると Table 4 の上5になる。右欄の $E I$ は Table. 3 々同様に, 横采効果を無視して計算した 1 $\mathrm{cm}$ 巾の布の $E I 飞 n^{\mathbf{s}}$ を乗じて見掛けの曲げ用さを計 算したものである。

試料 1 の平樴の $D, l_{0}, \theta$ は顕微鏡钼察すると, $l_{0} / D$ 
Table. 4

\begin{tabular}{|c|c|c|c|c|c|}
\hline$H$ & $\sin \theta$ & $n$ & $n^{3}$ & \multicolumn{2}{|c|}{$\begin{array}{l}E \overline{I=} \\
30.5 \times n^{8}\end{array}$} \\
\hline 0 & 0.250 & 1.143 & 1.493 & \multicolumn{2}{|c|}{45,5 dyne $\cdot \mathrm{cm}^{3}$} \\
\hline 0.2 & 0.225 & 1. 126 & 1. 428 & 43.6 & "1 \\
\hline 0.4 & 0.202 & 1.112 & 1.375 & 42.0 & " \\
\hline 0.6 & 0.177 & 1.097 & 1.320 & 40,5 & $" \prime$ \\
\hline 0.8 & 0.152 & 1.082 & 1.267 & 38.7 & $n$ \\
\hline 1.0 & 0.126 & 1.067 & 1.215 & 37.2 & $"$ \\
\hline 1.2 & 0.101 & 1.055 & 1.174 & 36.8 & " \\
\hline 1.4 & 0.075 & 1.040 & 1.125 & 34.4 & $" \prime$ \\
\hline 1.6 & 0.054 & 1.025 & 1.077 & 32.9 & $" \prime$ \\
\hline 1.8 & 0.025 & 1.013 & 1.039 & 31.7 & $" 1$ \\
\hline 2.0 & 0.000 & 1.000 & 1.000 & 30.5 & $n$ \\
\hline
\end{tabular}

$\div 3 \theta \div 30^{\circ}$ となりこれより $E I$ を剧算すると実験値 よりはるかに大きくなるが，これは $\theta$ を正碓に求められ ないことと，実蔡に曲什に抗束作用を及代す日はるつと 小さな值となるからだと执当すれる。これについては第 2 報18のようなモデル的な実験を目下準備中なので，い ずれかの機会に，より正確な考察を啹告したいと思つて いる。以上主として平織について取报つたが他組織につ れては別に考えたい。

\section{4. まとめ}

Heart loop 法で各種織物の曲げ附さを测定し，その 敍果飞基いて曲げのメカニズムを检討した。

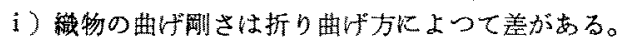

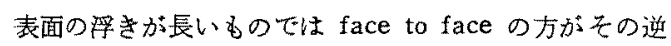
のよりEIは小さい。

ii）自由度の小さいもので一般に EI は小さいが， 㪴外多多。

iii）クリンブ効果は榴して小さく，ほとんど無視でき 马((8) 武)。

iv) 織り物の曲げ䣓さは根隣る糸の閒隔の有効唇の3 乗に比例するるのと考えられる。これをPeirce の織物
モデルを用いて解析してみた。実際の実験值とは必ずし も一致しないがかなり有効な説明がつくとおるわれる。

\section{5. あとがき}

本研究に当り㢦料その他の使宣を与えて戴いた本学部 防蟭研究会の諸氏, 文献その他御教示願つた本学工学部 木本害三教授ならびル金絧試料を御提供下さつた長野古 内山金網慗作所代感謝の意を表する次第でする。

\section{文缺}

1) F.T. Peirce; J. Text. Inst., 21, T 377(1930)

2）三浦乾太郎，一志湖夫，内田貞夫; 信大緎報告 No. 3, p. 81 (1953)

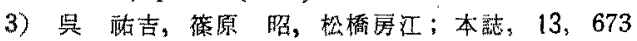
(1957)

4)一志淑夫; 瀻機誌, 9, 238 (1956)

5) A.E.H. Love; A Treatise of the Mathematical Theory of Elasticity, Cambridge (1952)

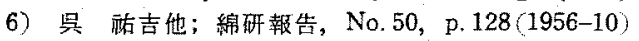

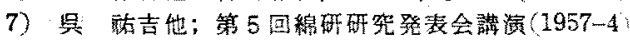
大服

8) R. Steele; Text. Res. J. 26, 739 (1956)

9) W. W. Barkas; Meredith's "Mechanical Properties of Wood and Paper" p.24 (1953), Amsterdom.

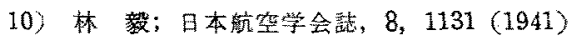

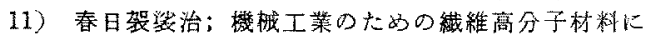

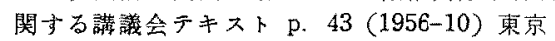

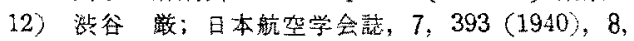
$267(1941)$

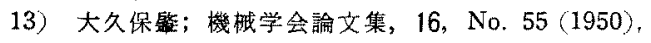
17, No.61 (1951)

14) 永盛義夫, 矢野勝雄; 底用力学, 3, 25 (1950)

15) 一志淑夫; 機誌, 7, 331 (1954)

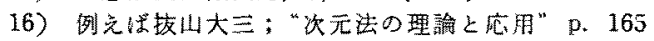
共立出版 (1956)

17) F.I.T. Peirce ; J.Text.Inst., 28, T45(1937)

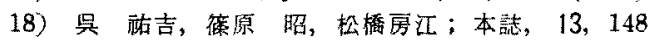
$(1957-3)$

本学会誌昭和 32 年総目次(1月号〜12月号)の別刷が若干ありますので御入要の方は版申越下さい。 実费送料共 50 円（切手で执执込み下さい)であります。 